\title{
A preliminary evaluation of the impact of Sulphur Emissions Control Area in the Baltic Sea on air quality in port cities. Case port - the city of Gdańsk
} \author{
Jastrzabek ${ }^{3}$, Tomasz Owczarek ${ }^{2}$ \\ ${ }^{1}$ Agency of Regional Air Quality Monitoring in Gdańsk Metropolitan Area \\ ${ }^{2}$ Faculty of Entrepreneurship and Quality Science, Gdynia Maritime University \\ ${ }^{3}$ Institute of Maritime Transport and Seaborne Trade, University of Gdańsk
}

Michalina Bielawska1, Oskar Czechowski², Ernest Czermański, Aneta Oniszczuk-

\begin{abstract}
The purpose of this research is to attempt to evaluate the extent, to which technical standards related to marine fuels and thereby also sulphur dioxide (SO2) content in engine exhausts from vessels operating on the Baltic Sea have been effective in curbing the negative impact of marine shipping on air quality, in particular in port cities. Marine environment protection is governed by the provisions of the MARPOL 73/78 International Convention, which Poland ratified as a party. Different areas of concern for marine shipping have been regulated in separate Appendices to the Convention. The first step was to introduce severe restrictions on SOx emissions in view of the fact that heavy marine fuel is the lowest-quality kerosene-derived fuel with a large content of sulphur. A gradual process was put in place to reduce its content in marine fuel. As a consequence, the world's marine areas were divided into sulphur emission control areas (also known as SECA) and other areas. In Europe, these areas include the entire Baltic Sea and large portions of the North Sea. Another important technical and economic measure was to lower the limit of sulphur content in marine fuel to $0.1 \%$ in all SECA areas, with the limits remaining unchanged in the other areas. Two dates were of key importance for the investigation: 2010, when the reduction in sulphur content of marine fuels from $1.5 \%$ to $1 \%$ was mandated, and 2015 , when the standard for sulphur content was dramatically lowered to $0.1 \%$. In the first stage, the concentration of sulphur dioxide was researched as one of the factors preceding air contamination with suspended particles in the Gdańsk Gdynia area in the period from 2005 to 2016, as investigated by four automatic reference measurement stations in the ARMAAG network (hourly data) located in the immediate vicinity of the sea (AM4, AM5, AM6 and AM8). The research concerned the arrival of high concentrations of sulphur blown in from the sea by the wind. Another key factor was the secondary data on the number of ships, in the form of monthly series, starting from 2007. The analysis was performed in stages. In the first stage, the quality of measurement and secondary data were evaluated using a unique data quality assessment method. Further on, Principal Component Analysis (PCA) models were constructed to identify spatial correlations between $\mathrm{SO} 2$ concentration distributions, which were used later as a basis on which to determine synthetic measures of average hourly concentrations for the entire agglomeration area. Subsequently, the impact of the $\mathrm{SO} 2$ source (influx from the Baltic Sea to the agglomeration areas) was gauged separately for each individual station. The PCA models constructed on the basis of hourly data corroborated the synthetic measures as correct, making
\end{abstract}


it possible to identify the similarity of concentration distributions across the investigated stations. Multi-Dimensional Regression Models and Generalized Regression Models (GRM) have made it possible to identify the period, in which the concentration of sulphur dioxide dropped steadily (from 2010 to 2016), as well as the seasonal impact of variation in SO2 concentration and the number of ships. The hourly data was converted to average monthly, quarterly and annual values, depending on the mathematical model and purpose of research.

Keywords: shipping, Sulphur Regulation, ship emissions, port emissions, port - city correlation, port of Gdansk

\section{Introduction}

Human activity at sea generates serious consequences for the environment and society. The activity is therefore heavily regulated by international and national rules and acts. One of the most important legal acts in recent years, dedicated to the environment (with a focus on the sea) is the MARPOL 73/78 - International Convention for the Prevention of Pollution from Ships. The entire act, with a number of annexes, has been introduced to address the following concerns: oil pollution (I), noxious liquid substances (II), sewage (IV), garbage (V) and the prevention of air pollution by ships (VI). The Annex VI standards came into force in May 2005. This act established the Emission Control Areas (ECA - an area where special mandatory measures are required to control $\mathrm{NO}_{2}, \mathrm{SO}_{2}$ and particulate matter (PM), or all the three types of emissions from ships) with a global cap of $4.5 \%$ on the sulphur content in fuel and a $1.5 \%$ limit in SECA (Sulphur Emission Control Area) zones. Standards for $\mathrm{SO}_{2}$ limits were incorporated into EU law by Directive 1999/32/EC, as amended by Directive 2005/33/EC. The Directive also set two additional $\mathrm{SO}_{2}$ limits for EU member states: $1.5 \%$ for passenger vessels operating regular services from 2006 , and $0.1 \%$ for ships at berth from 2010. Generally, ECAs were established across the whole Baltic Sea area (see Fig. 1.1) - as defined in Annex I of MARPOL ( $\mathrm{SO}_{2}$ only). The latest $\mathrm{SO}_{2}$ limits allowing a maximum $0.1 \%$ of sulphur content in marine fuel in SECA zones came into force as of 1 of January 2015. This was predicted to mark a serious technical and economic turning point for shipping companies in the Baltic Sea Region [1].

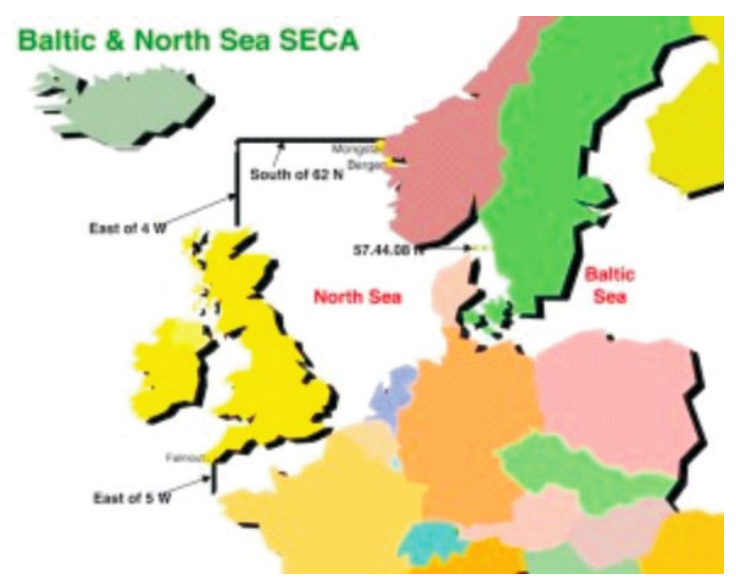

Figure 1. Baltic and North Sea SECA zone established by Annex VI MARPOL 73/78.

Source: [2] 
MARPOL Annex VI means therefore a serious reduction of sulphur pollution in the SECA zones and, naturally, in coastal regions and especially ports and port cities. Due to the on-going debates, the current tendency to tighten restrictions and establish worldwide sulphur content limits on marine fuels, it seems that as of 2020 , a limit of $0.5 \%$ will be enforced for global maritime transport.

This research paper is an attempt to evaluate the effectiveness of the implementation of MARPOL Annex VI in terms of limiting sulphur content in cities with large sea ports located within their boundaries. The object of this research will be to test the quality of air based on its sulphur oxide content, having regard also to such relevant factors as air temperature, wind force and direction, and vessel traffic at port.

\section{Methodology}

\subsection{Models}

In order to verify the hypotheses, models were selected for use with the adopted research procedure, depending on the measurement scales of the empirical, stochastic and exploratory variables and assumptions under investigation. Among the key models the following should be mentioned: simple models of the ANOVA family in averages compared and multidimensional principal component (PCA) models, as well as advanced generalized regression models (GRM). The obtained results allowed the implementation of all the assumed research goals. At the same time, their cognitive value is high not only in scientific but also in practical terms.

The GRM models were used to identify factors in weak measurement scales, i.e.: nominal and ordinal scale, in addition to (impact of time periods on $\mathrm{SO}_{2}$ concentration) and in conjunction with the strong scale. GRM is a path rather than a model. It subsumes many classical models (e.g. ANOVA, MANOVA) into one simple model. It allows testing the effects and interactions. Simple models are easier to put to test again in replication and cross-validation studies, less costly to put into practice in predicting and controlling the outcome in the future and - last not least - allow using, to a larger extent than individual models taken separately, a wider range of fit statistics and diagnostic calculations, example leverages and outlier observations.

The analysis of variance (ANOVA) is used to determine whether there are any statistically significant differences between the means of two or more independent (unrelated) groups (levels of one variable in weak measurement scales) in the one-way ANOVA or two variables in the two-way ANOVA with interactions.

The one-way ANOVA compares the means between the groups we are interested in and determines whether any of those means are statistically significantly different from each other. Specifically, it tests the null hypothesis:

$$
H_{0}: \mu_{1}=\mu_{2}=\mu_{3}=\cdots=\mu_{k}
$$

where $\mu$ group mean and $\mathrm{k}=$ number of groups. If, however, the one-way ANOVA returns a statistically significant result, we accept the alternative hypothesis $\left(\mathrm{H}_{1}\right)$, which is that there are at least two group means that are statistically significantly different from each other [6,7].

\subsection{Research procedure}


The adopted research procedure explored $\mathrm{SO}_{2}$ concentration as an indication of other concentrations. Further on, the other contaminations and their compounds, such as suspended dust, nitrogen oxides and others, will be looked at.

Of key importance were the two dates when new standards were introduced: 2010 when the permissible content limit of sulphur was lowered from $1.5 \%$ to $1 \%$ and 2015 when sulphur content was slashed dramatically to $0.1 \%$. The first-stage investigation covered sulphur dioxide concentration (designated as $\mathrm{SO}_{2}$ or $\mathrm{SO} 2$ on computer printouts) as one of the indicators of air pollution with suspended particles in the Tricity area from 2005 to 2016, as measured at one of the four automatic survey stations within the ARMAAG network (hourly data) posted in the immediate vicinity of the sea (AM4, AM5, AM6 and AM8).

Initially, the research additionally looked at the results of concentration measurements for $\mathrm{SO} 2$ at $\mathrm{AM} 2$ and $\mathrm{AM} 3$ stations, but these series were ignored in the subsequent stages of the research for technical reasons.

The variables were series of results collected at hourly intervals between 1 January 2005 to 31 December 2017 (113950 items). In fact, they are continuous measurements recorded on the ARMAAG surveillance system, sectioned into hourly intervals and averaged accordingly. Besides the measurement result series for $\mathrm{SO}_{2}$ concentrations, the research used hourly measurements of wind speed and direction for each station separately. The measurement results for $\mathrm{SO}_{2}$ concentrations after factoring in the direction of wind from the sea were designated as " $\mathrm{SO}_{2}$.wsea".

The data on the number of ships come from the Port of Gdańsk. These are numerical strings representing the number of ships entering and leaving the Port of Gdańsk in the years $2010-2017$.

Depending on the purpose of the investigation and the applied mathematical model, the original daytime strings were averaged (concentrations) or combined (number of ships) to match the required monthly or annual cycles.

The research was completed in stages. In the first stage, all the series were tested for quality by two methods: a manual method carried out in operational mode by the ARMAAG foundation employees and an automatic method based on proprietary algorithms of measurement data diagnostics [3]. Only verified data were considered in further research.

The next stage involved the construction of PCA (Principal Component Analysis) models in order to identify the mutual relations in spatial distributions of $\mathrm{SO}_{2}$ concentrations to provide a basis for determining the synthetic measures used to select the average hourly $\mathrm{SO}_{2}$ concentrations for the entire agglomeration area.

For each year separately, PCA models were constructed for $\mathrm{SO}_{2}$ concentration measurements at each station for all wind directions and for all $\mathrm{SO}_{2}$ concentration measurements only for seaward winds.

For the first principal components (PC1) and second principal components (PC2) in the years 2005 - 2016, for all wind directions and seaward winds, Pearson total correction factors were calculated between the current and the previous year (designation: lag 1), as presented in Fig. 2. Starting from 2013, the correlation values are high ( 0.8 for PC1 and 0.5 for PC2) and stable, indicating a high degree of similarity of the phenomenon's structure. The earlier years $(2009-2012)$ are characterized by dynamic change, exhibiting in full the dynamics within the relations of $\mathrm{SO}_{2}$ concentrations at the individual stations year after year. For PC1, the correlation increase from 0.1 between 2010 and 2011, and to 0.9 between 2013 and 2012 means a complete change in the relations of $\mathrm{SO}_{2}$ concentrations across the entire coastal area for concentrations accumulated from the seaward directions (Figure. 2 left). 

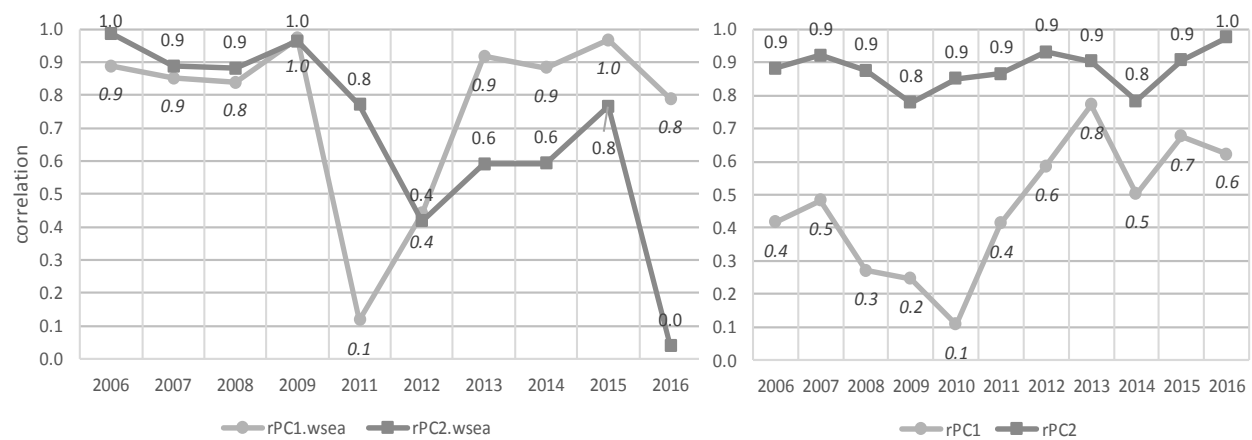

Figure 2. Correlation between PC1 and PC1 lag 1 year in PCA structure models; left: wind speed from sea, right all wind directions.

Source: The authors' own elaboration based on Agency of Regional Air Quality Monitoring in Gdańsk Metropolitan Area.

The PCA models for $\mathrm{SO}_{2}$ concentrations confirmed that it was a correct decision to leave out the AM2 results due to the completely different type of measurement they represented (Figure 3). This was related to the fact that $\mathrm{SO} 2$ concentrations at the location of the AM2 station are impacted by emissions from large and troublesome industrial developments (refinery, power plant) and the densely forested surrounding area.

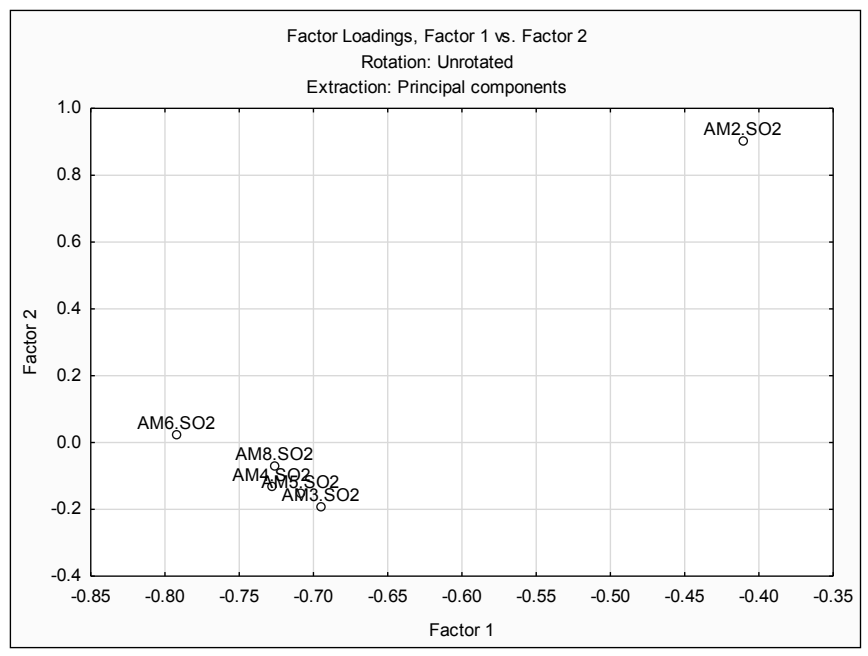

Figure 3. Model PCA results (2005-2016) from all stations and all wind directions.

Source: The authors' elaboration based on Agency of Regional Air Quality Monitoring in Gdańsk Metropolitan Area. 


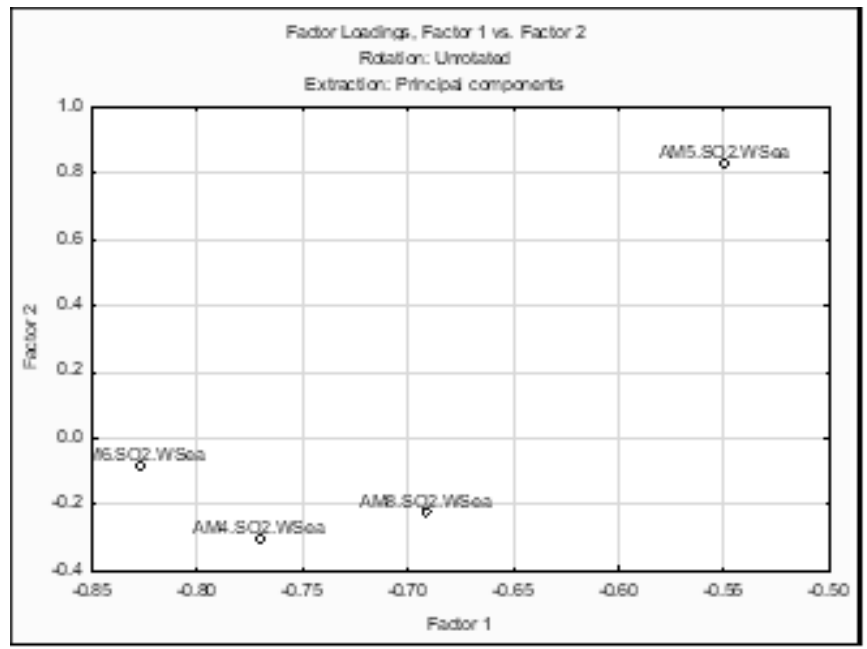

Figure 4. Model PCA results (2005-2016) from selected stations and wind directions from sea.

Source: The authors' own elaboration based on Agency of Regional Air Quality Monitoring in Gdańsk Metropolitan Area.

Ultimately, the following stations were qualified for further research: AM4, AM5, AM6 and AM8. Their mutual relations, together with the direction of the seaward wind, are presented in Figure 5. The AM5 station is located a little further inland, therefore its results differ slightly from the others'; in that sense, it forms the background for those stations situated closer to the sea. Ultimately, the PCA models for $\mathrm{SO}_{2}$ concentrations were compared with no regard to the wind direction and models for the direction of seaward winds (Figure 6); at the same time, the models were calculated for one-hour data and any gaps were filled with averaged figures. The models thus identified exhibit a high degree of similarity, which serves as proof that the right stations have been chosen for further investigation. 


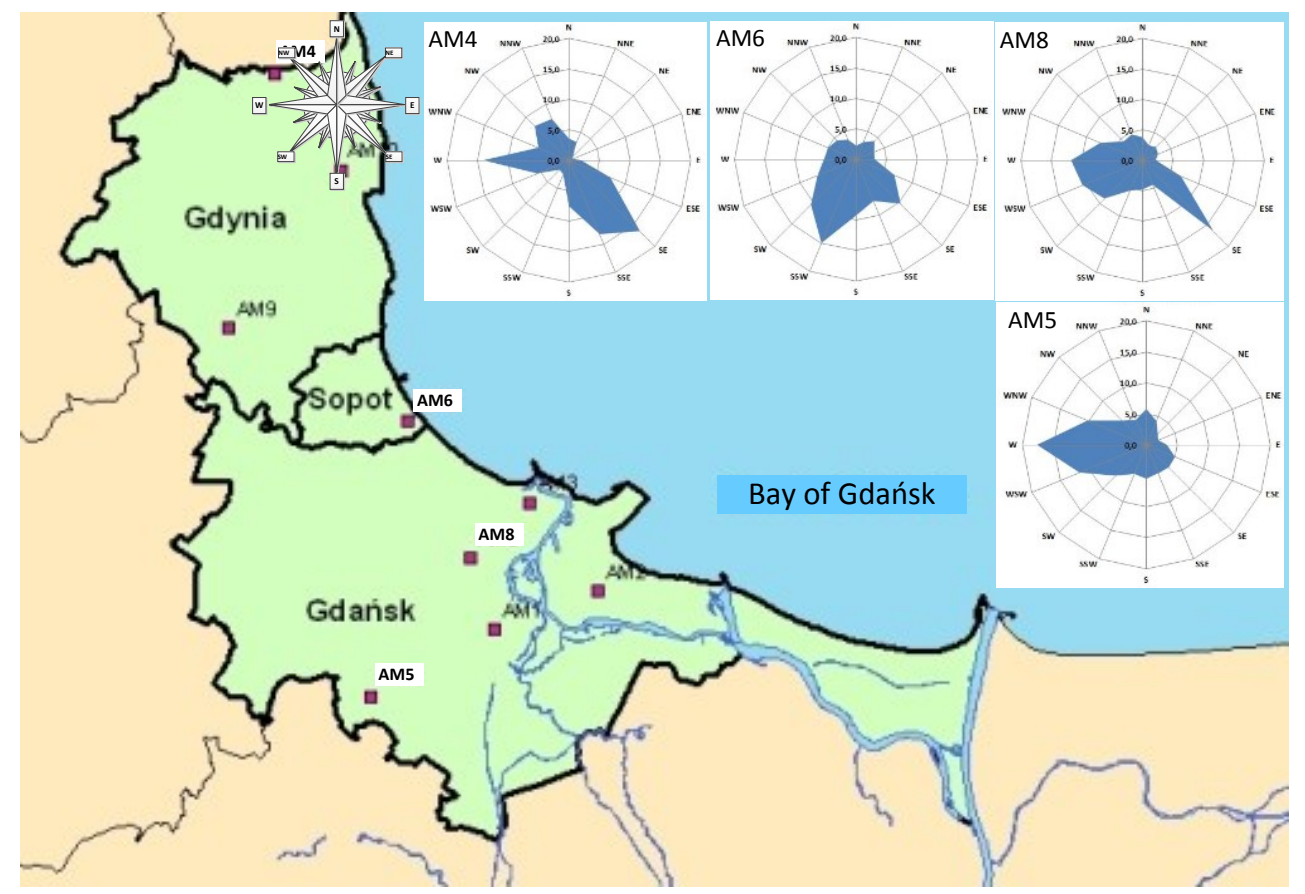

Figure 5. Wind roses (2010-2017) on selected ARMAAG stations.

Source: The authors' own elaboration based on Agency of Regional Air Quality Monitoring in Gdańsk Metropolitan Area.

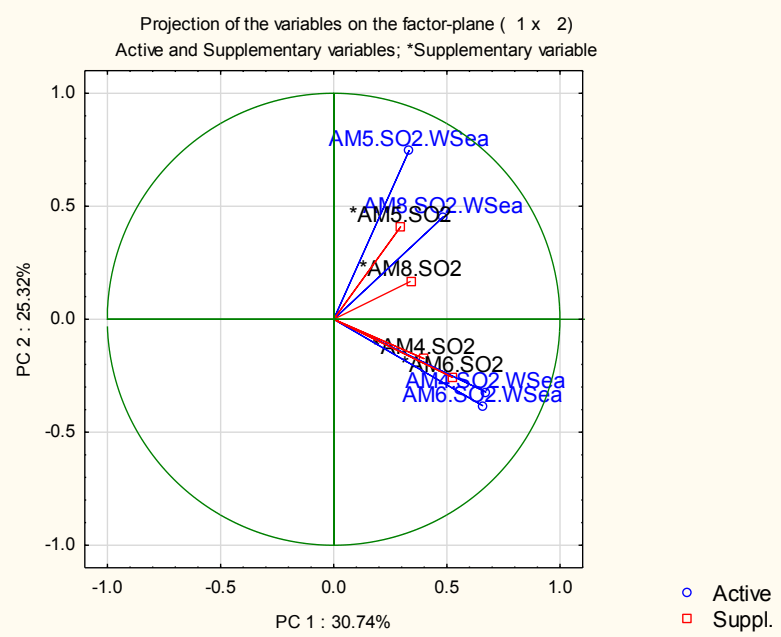

Figure 6. Comparison of PCA models: all wind directions and from the sea.

Source: The authors' own elaboration based on Agency of Regional Air Quality Monitoring in Gdańsk Metropolitan Area.

Further calculations were based on synthetic measures for the entire area and these were used to select averages for the four stations. Two measures of $\mathrm{SO}_{2}$ concentrations were calculated for hourly results in accordance with 
Table 1: for all wind directions and for seaward winds which accumulate the largest amount of $\mathrm{SO}_{2}$ emissions from ships onto the coastal and agglomeration areas.

Table 1. Wind directions and ranges in deg in selected stations

\begin{tabular}{|l|l|l|}
\hline Station & Wind direction from sea & Range in deg \\
\hline AM4 & From N to SE & $349-360 ; 1-146,99$ \\
\hline AM5 & From NNE to ENE & $12-78,99$ \\
\hline AM6 & From N to ESE & $349-360 ; 1-123,99$ \\
\hline AM8 & From N to E & $1-101,99$ \\
\hline
\end{tabular}

Source: The authors' own elaboration based on Agency of Regional Air Quality Monitoring in Gdańsk Metropolitan Area.
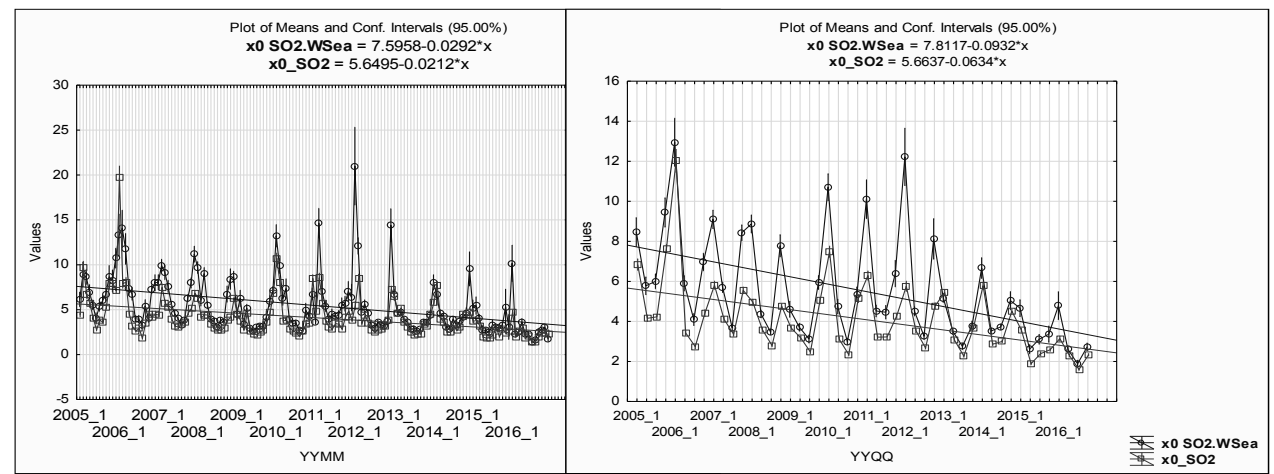

Figure 7. $\mathrm{SO}_{2}$ monthly (MM) and quarterly (QQ) averages in year (YY) from 2005 to 2016 with OLS trend lines

Source: The authors' own elaboration based on Agency of Regional Air Quality Monitoring in Gdańsk Metropolitan Area. 


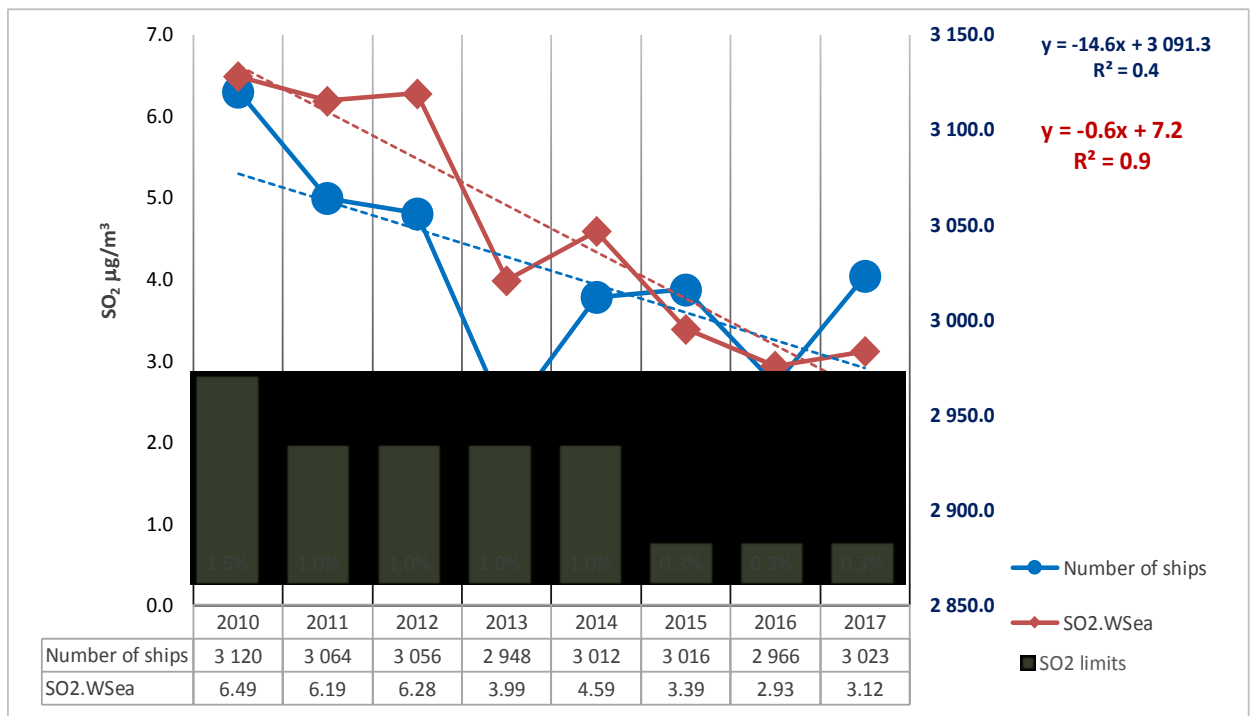

Figure 8. $\mathrm{SO}_{2}$.wsea time series. number of ships with OLS trend models identification with $\mathrm{R}^{2}$ and $\mathrm{SO}_{2}$ limits

Source: The authors' own elaboration based on Agency of Regional Air Quality Monitoring in Gdańsk Metropolitan Area, Maritime Office in Gdynia.

Figure presents a summary of change patterns in the average $\mathrm{SO}_{2}$ concentrations brought in from the sea, as measured by four coastal stations, changes in the number of ships leaving the port of Gdańsk and the percentage limits on sulphur in the individual years.

As mentioned earlier on, the new, more restrictive norms for $\mathrm{SO}_{2}$ emissions $(0.1 \%)$ were introduced in early 2015. Ship owners had had over 5 years to comply with the requirement, even though an overwhelming majority of them had decided to wait until the last minute before making decisions regarding the adoption of technological strategies and solutions allowing ships to operate in compliance with the new rules. Few of them had undertaken any work on new fuels (e.g. Stena Line - methanol) or fume purification technologies (Finnlines - scrubber). Most of them decided to switch over to MGO (Marine Gas Oil). After a short period of uncertainty between 2014 and 2015, the situation has not stabilized. The research results have now shown the real efficacy of the implemented Sulphur Directive.

Despite a small hike in the number of ships (3016) compared to the corresponding figure for 2014 (3012), average $\mathrm{SO}_{2}$ concentrations fell dramatically from $4.59 \mu \mathrm{g} / \mathrm{m}^{3}$ in 2014 to $3.39 \mu \mathrm{g} / \mathrm{m}^{3}$ in 2015 . The following years showed the level of average $\mathrm{SO}_{2}$ concentration accumulated from the seaward direction into Gdańsk Metropolitan Areas stabilizing at $3.00 \mu \mathrm{g} / \mathrm{m}^{3}$ even despite the increase in the number of ships from 2966 in 2016 to 3023 in 2017.

Especially remarkable are the effects of imposing new limits on concentration on land. In 2015-2016,even despite a growing number of ship calls, the concentration level is significantly lower compared with 2014, just before the new regulations were implemented (Table 2). A similar trend for $\mathrm{SO}_{2}$ concentrations could be observed even earlier, i.e. from 2011 (Fig. 8). At that time, however, a dramatic drop in $\mathrm{SO}_{2}$ concentrations did not come until two years later (2013) even though the number of ships remained constant. 
Table 2. Percentage changes in $\mathrm{SO}_{2}$ concentrations and the number of ships compared to 2014

\begin{tabular}{|r|r|r|l|l|}
\hline Year & $\begin{array}{l}\text { SO2.Wsea } \\
\text { average }\end{array}$ & $\begin{array}{l}\text { Number } \\
\text { of ships }\end{array}$ & $\begin{array}{l}\text { SO2.Wsea } \\
\text { percentage } \\
\text { change to 2014 }\end{array}$ & $\begin{array}{l}\text { Number of ships } \\
\text { percentage } \\
\text { change to 2014 }\end{array}$ \\
\hline $\mathbf{2 0 1 4}$ & $\mathbf{4 . 5 9}$ & $\mathbf{3 0 1 2}$ & & \\
\hline 2015 & 3.39 & 3016 & $-26.1 \%$ & $0.1 \%$ \\
\hline 2016 & 2.93 & 2966 & $-48.7 \%$ & $-1.5 \%$ \\
\hline 2017 & 3.12 & 3023 & $-50.1 \%$ & $0.4 \%$ \\
\hline
\end{tabular}

Source: The authors' own elaboration based on Maritime Office in Gdynia.

For the relevant period of 2010 - 2016, trend models were constructed (Bląd! Nie można odnaleźć źródła odwołania.), fit measures were calculated ( $R, R 2$, corrected R2 and RMSE) and overall model relevance was checked ( $\mathrm{F}$ test with $\mathrm{p}$ level and the relevance of each parameter based on t-Student distribution)[3]. Trend models for $\mathrm{SO}_{2}$ concentrations both for seaward wind and a variable number of ships leaving the port are statistically relevant $(\mathrm{p}<=0.05)$. Both models indicate a falling trend.

Table 3. Pearson moment correlations; Marked bold correlations are significant at $\mathrm{p}<.05000$ (20102016)

\begin{tabular}{crrrr}
\hline Variable & $\begin{array}{c}\text { Number of } \\
\text { ships }\end{array}$ & $\mathrm{SO}_{2}$.WSea & $\mathrm{SO}_{2}$ limits & \multicolumn{1}{c}{$\mathrm{SO}_{2}$} \\
\hline Number of ships & 1.0 & $\mathbf{0 . 8 5}$ & 0.63 & 0.68 \\
$\mathrm{SO}_{2}$.WSea & $\mathbf{0 . 8 5}$ & 1.0 & $\mathbf{0 . 8 3}$ & $\mathbf{0 . 9 2}$ \\
$\mathrm{SO}_{2}$ limits & 0.63 & $\mathbf{0 . 8 3}$ & 1.0 & $\mathbf{0 . 9 4}$ \\
$\mathrm{SO}_{2}$ & 0.68 & $\mathbf{0 . 9 2}$ & $\mathbf{0 . 9 4}$ & 1.0 \\
\hline
\end{tabular}

Include condition: Year $>=2010$ AND Year $<=2016$

Source: The authors' own elaboration based on Maritime Office in Gdynia.

Correlation analysis (

Table 3) for the period from 2010 to 2016 seems particularly interesting for the purpose of this research. $\mathrm{SO}_{2}$ concentration limits are significantly and strongly correlated with $\mathrm{SO}_{2}$ concentrations on land, both overall concentrations (0.94) and concentrations with the wind direction factored in (0.83). There is a strong and relevant statistical correlation between the number of ships leaving the port $(0.85)$ with $\mathrm{SO}_{2}$ concentrations accumulated from the sea into Gdańsk Metropolitan Area, as corroborated both by the impact of $\mathrm{SO}_{2}$ emissions from the sea and the positive long-term effects of the new limits. The impact of $\mathrm{SO}_{2}$ emissions from the sea on the air in the metropolitan area causes negative health effects, as confirmed by many years of research $[4,5]$.

\section{Conclusions}

The following conclusions emerged in the first stage of research on the impact of new, more restrictive norms on the content of sulphur in marine fuel: 
1. The impact of $\mathrm{SO}_{2}$ concentrations emitted by fuel combustion in ships on the air in the Tricity area is noticeable and felt by the residents.

2. There has been, since 2010, a steady year-by-year decrease of average $\mathrm{SO}_{2}$ concentration by $0.6 \mu \mathrm{g} / \mathrm{m}^{3}$ for the whole area. For the Tricity area, this is a considerable drop $(\mathrm{p}<=0.05)$ of $\mathrm{SO}_{2}$ concentrations emitted by fuel combustion by ships operating at sea.

3. The largest decrease of $\mathrm{SO}_{2}$ concentrations arising from marine fuel combustion at sea has been noted since 2015. This trend is a positive effect of the new norms for sulphur content in marine fuel.

4. In 2015, despite a hike in the number of ships, from 2948 in 2014 to 3016 in 2016, the average level of $\mathrm{SO}_{2}$ concentration fell in the entire area from $4.6 \mu \mathrm{g} / \mathrm{m}^{3}$ in 2014 to 3.4 $\mu \mathrm{g} / \mathrm{m}^{3}$ in 2015 and to $2.9 \mu \mathrm{g} / \mathrm{m}^{3}$ in 2016 .

5. Table 2 suggests that the new 2015 limits reduced the estimated level of $\mathrm{SO}_{2}$ accumulated by wind into Gdańsk Metropolitan Area by around 50\% compared to the same figure in 2014 (the year when the directive came into force) even despite a $0.4 \%$ increase of the number of ships calling at the port.

To sum up, it can be concluded that the entry into force of the Sulphur Directive has benefited the port city of Gdańsk through improved air quality and a reduction of $\mathrm{SO}_{2}$ content in the air.

\section{Discussion}

The conducted research and the resulting outcomes indicate a high (50\%) effectiveness in reducing the sulphur content in the air in port cities as a consequence of the Sulphur Directive. However, two issues should be stressed which prevent us from relating the results to the entire Baltic Sea Region, not to mention the whole globe.

First of all, the research was carried out based on data for only one city, Gdańsk. Apart from methodological correctness which was assured at every stage of the investigation, conclusions have emerged that dictate the need for analogous research to be conducted as well for other port cities situated in the Baltic Sea region or, indeed, the entire Baltic Sea. However, this requires considerable financial resources and infrastructural adjustments at the ports in question. It should also be remembered that many ports, or port cities, do not have any system in place to allow measurement of air pollution.

Secondly, the technologies used by ships calling at the port of Gdańsk are unknown, making it difficult to determine which of the technologies implemented by ship owners on the Baltic Sea have contributed to the current state of affairs and to what extent. It is said that open-loop scrubbers, for example, purify their fumes by diverting the sulphur produced in the process back into the sea waters. It is also noteworthy that the Baltic waters are especially heavily polluted, including by hydrogen sulphide. Therefore, the $50 \%$ reduction in $\mathrm{SO}_{2}$ content in the air could have been better or worse depending on the specific technology adopted by ship owners themselves. This may in turn be determined indirectly by the port management bodies through a system of preferences and price discounts for those ships which are the most environmentally friendly.

\section{References:}


[1] E. Czermański (ed.), Sulphur Regulation - technology solutions and economic consequences for the Baltic Sea Region shipping market, Institute of Maritime Transport and Seaborne Trade, Sopot 2014.

[2] eceurope.net/wp-content/uploads/2007/08/seca1, 14/03/2014.

[3] P. O. Czechowski, A. Badyda, G. Majewski, Data mining system for air quality monitoring networks, Archives of Environmnetal Protection 39/4/p123-144, 2013 DOI: 10.2478/aep-2013-0041.

[4] A.J. Badyda, P. Dąbrowiecki, P.O. Czechowski, G. Majewski, Risk of bronchi obstruction among non-smokers-Review of environmental factors affecting bronchoconstriction, Respiratory physiology \& neurobiology, Elsevier 2015/4/1, 209.

[5] P.O. Czechowski, A.J. Badyda, G. Majewski, A. Oniszczuk-Jastrząbek, A.K. Kraszewski, W. Rogula-Kozłowska, T. Owczarek, Providing high-quality measurement data in analytical system of air pollution monitoring and their key importance for smart cities residents, Annals of Warsaw University of Life Sciences-SGGW. Land Reclamation, De Gruyter Open 2017/12/1, 49, p. 241-253.

[6] D.G. Kleinbaum, L.L. Kupper, A. Nizam, K.E. Muller, Applied Regression Analysis and Other Multivariable Methods (Duxbury Applied) 4th Edition, 2008, ISBN 9780495384960.

[7] G. Majewski, W. Rogula-Kozłowska, P.O. Czechowski, A. Badyda, A. Brandyk, The impact of selected parameters on visibility: First results from a long-term campaign in Warsaw, Poland, Atmosphere, Tom 6, Wydanie 8, Strony, p.1154-1174. 